\title{
The impact of work-based research projects at postgraduate level
}

\begin{abstract}
Purpose - The purpose of this paper is to examine the impact of work-based research projects at postgraduate level. The focus of this paper is to measure the impact of masters- and doctoral-level work-based projects which was the specific contribution of one group of researchers to the Nixon et al.'s (2008) study.

Design/methodology/approach - This paper is based on data generated as part of a wider study that examines the impact of work-based learning projects across undergraduate through to doctoral level from the perspective of employers and from the employees perspective. The research study is based on a sample of alumni who had graduated from work-based masters and professional doctorate programmes and their corresponding employers in a UK higher education institution.

Findings - At masters and doctorate level the work-based project can often make an impact on the work context and also have a developmental effect on the employee who becomes a practitioner-researcher to undertake the project.

Originality/value - This paper finds that work-based projects are often an investment that companies make that have the propensity to yield tangible business success as well as providing an incentive for key staff to remain in the company and achieve university recognition.
\end{abstract}

Keywords Work-based learning, Higher education, High-level skills, Work-based projects, Motivation and support, Personal and professional confidence

Paper type Research paper

\section{Introduction}

Work-based research and development projects are usually the key element of work-based and professional studies awards. These are awards in the transdisciplinary field of work-based learning (WBL). WBL awards are normally defined in generic terms and are applicable to people in any kind of work situation at any level. WBL awards can be categorised as an individually negotiated programmes or cohort-designed programmes and comprise of a full range of award-bearing programmes from certificate to doctorate.

The term "studies" relates to the generic abilities that are common to high-level skills and knowledge that are desirable for work. Assessment is in relation to generic learning outcomes: for example, the ability to synthesise, analyse and evaluate, work in a team and autonomously identify and select appropriate resources. Participants undertake modules involving "Accrediting of Prior and Experiential Learning" (APEL) or called "Recognition of Prior Learning" (RPL) (Garnett et al., 2004), "reflective writing activities", "planning and learning agreements", "research and development for

(C) Carol Costley \& Abdulai Abukari. Published in the Journal of Work-Applied Management. This article is published under the Creative Commons Attribution (CC BY 4.0) licence. Anyone may reproduce, distribute, translate and create derivative works of this article (for both commercial and non-commercial purposes), subject to full attribution to the original publication and authors. The full terms of this licence may be seen at http://creativecommons.org/licences/by/4.0/legalcode

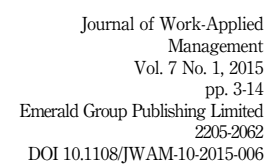


JWAM

7,1

professional practice" (Garnett et al., 2008). The unique approach to whole awards has been extremely successful over the past $20+$ years attracting large numbers at all levels especially in the UK.

This paper is based on data generated as part of a wider study that examines the impact of WBL projects across undergraduate through to doctoral level from the perspective of employers and from the employees perspective (Nixon et al., 2008). The focus of this paper is to measure the impact of masters- and doctoral-level work-based projects which was the specific contribution of one group of researchers to the Nixon et al. (2008) study. The research study is based on a sample of alumni who had graduated from work-based masters and professional doctorate programmes and their corresponding employers in a UK higher education institution (HEIs). As the WBL programmes recruit both home and international students, the participants in the research came from different countries including the UK (majority), Ireland and Australia. The results of the study are then used to track the impact of work-based projects undertaken with subsequent and various employer groups (see e.g. Costley and Critten, 2012).

At masters and doctorate level the work-based project can often make an impact on the work context and also have a developmental effect on the employee who becomes a practitioner-researcher to undertake the project. The practitioner-researchers are engaged in solving highly contextualised problems and do this to develop their practice at work supported by high-level university learning and teaching. Work-based projects are often an investment that companies make that have the propensity to yield tangible business success as well as providing an incentive for key staff to remain in the company and achieve university recognition. The paper starts with an overview of the context to the research study; this is followed by a discussion of work-based curriculum for professionals and an outline of the research methodology. The finding is then presented and discussed, followed by a set of recommendations and conclusion.

\section{A work-based curriculum for professionals}

The Institute for Work Based Learning at Middlesex University defines WBL at university level as a:

[...] learning process which focuses university level critical thinking upon work (paid or unpaid) in order to facilitate the recognition, acquisition and application of individual knowledge, skills and abilities, to achieve specific outcomes of significance to the learner, their work and to the university (Gibbs and Garnett, 2007).

There are other definitions of WBL that overlap this one as the field is complex and spans all levels and affords different priorities. What does remain a constant set of concepts involves approaches to knowledge that embrace a wide practice-based contribution to knowledge, approaches to learning and teaching that place the learner as having practice expertise and the teacher as facilitator of that expertise and experience. Postgraduate level WBL usually uses a flexible model that engages with employer-employee-university in a three-way learning agreement that can range in its function. The most profound and close relationship is working closely with the employer in a partnership agreement with the university where the employer contributes significantly to the content of the programme including the nature of the work-based project. At the opposite end of the spectrum of possibilities in the three-way agreement is an individual having their agreement signed by a senior professional in the field whose main purpose is to endorse the work-based project as an appropriate research and development activity. 
WBL at masters and doctoral level emphasises learner-centred and reflective practice. It views work-based knowledge as knowledge produced in the context of application; at the same time conceiving knowledge as a means of advancing practice with utilitarian benefits and underpinning practice with critical discourse on existing knowledge. The frontier of the higher education knowledge base is then extended and the benefits of higher education are more directly applied to work settings (Lester and Costley, 2010).

WBL as an area in higher education is able to meet some of the current needs relating to "complexity" (Shaw, 2002). One of the ways WBL has been able to do this is by acknowledging high-level experience through APEL/RPL. Many work-based learners build on their existing "formal university qualifications" to undertake programmes, others undertake programmes based on their existing experiences and the accumulated knowledge through APEL/RPL rather than formal university qualifications, starting the programme at the actual point of the learners' current understanding. Thus legitimacy is given to previous and current work and through a reflective process learners are able to relate their work-based practice to theory.

Students are free to make sense of their context and in this sense, agency, position and situatedness are key factors. Situatedness (Lave and Wenger, 1991) is the development of individual intelligence requiring both social and cultural influences. It arises from the interplay between the researcher, the situation (the particular set of circumstances and the researcher's position within it) and context (where, when and the background that provides the multiple perspectives needed for understanding). Organisational, professional and personal contexts will affect the way a piece of research and development is undertaken.

\section{The study}

Participants in the 2008 study were limited to employees who completed WBL programmes at masters and doctorate levels (individual negotiated programmes and cohort-designed programmes). These have been merged in this analysis because they have similar characteristics in terms of the role of individual students in designing their programmes; the main difference being that in the former, students undertook study as individuals from different organisations while in the latter, students undertook study as part of a group, usually from the same organisation. The employees (WBL graduates) and their corresponding employers (where possible) participated in the study (see Table I).

The research involves gathering data using semi-structured interview discussion guides for employees and employers that had seven distinct categories; context, motivation, needs, programme of study, benefits and impact, value for money, other. These are provided by the Higher Education Academy as the research formed part of a larger research project at all levels of higher education (Nixon et al., 2008).

The approach used throughout this study is to understand the constructions that the employees and employers held, through analysis, interpretation, critique and iteration to arrive at findings that contain credible and improved understanding (Lincoln and Guba, 2000; Schwandt, 1998). Placing this perspective within the context of the WBL impact study, the research sought to understand the individual views of employers and employees about the benefits and impact of work-based projects and then through reflective analysis, offer some recommendations.

The participants in the Nixon et al. (2008) study are "purposive sampled" (Neuman, 2003); so in order to meet the participant sample limit of employees (and their corresponding employers) that is representative of the nature of masters and doctorate awards at the university, it is important to strategically select people across the spectrum.
Work-based research projects 


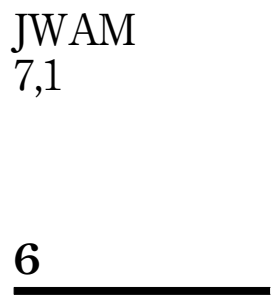

Table I.

Examples of some of the case studies

Title of work-based project
A communications framework for inclusivity: an action
research approach to providing information
Development of a counselling and psychotherapy
supervision training programme within an Australian
educational context
Developing changes for Irish non-profit organisations

An investigation, evaluation and development of techniques to enable the spread and adoption of innovative practices, based on the Trent region older people services project

Adopting a holistic approach to the valuation of learning programmes deployed in corporate environments

The development of the professional accreditation of conservator - restorers

Digital futures: e-commerce and sustainable development (individually negotiated programme). The Thinktank masters element of the programme is cohort-based (same as R) The one certainty in life - an action research inquiry: Financial improving Lloyds TSB asset finance division's Institution capability to help people through change and transition Manager Marks and Spencer food section managers - the Retail enablers to delivery of exceptional individual work Manager performance
Sector Award

MA in Professional

Graphic designer Practice

Private Doctor of Professional

Consultant Studies

psychotherapist

Private MA Work-Based

Consultant - Learning Studies

Charities

Private

Doctor of Professional

Consultant - $\quad$ Studies

Health management

Public

Education and training

Private

Education and training

Public

Doctor of Professional

Studies

Doctor of Professional

Studies

Doctor of Professional Studies

MA Studies WBL

(Leadership and

Management Practice)

MA Studies WBL (Retail

Management)

A reflexive reading is taken based not only on the cases and their contexts, but also the experiences of the researchers as part of the process of investigation. One important role of the reflexive reading is not only to channel the researchers' views into the interpretation process but also to incorporate the views of focus groups and to make critical reflections to check biases that could influence the process. The examples up to 2013 did not include focus groups and used random samples but used the same questionnaire and analytical framework.

\section{Key findings of the benefits and impact of work-based projects}

\section{Motivation and support}

The main motivations for employees undertaking WBL are of personal enthusiasm, the desire to develop oneself and to gain more professional expertise. Employers' motivations are more centred on the view that employees form the cornerstone of organisations and the development of their skills and competency will invariably lead to improved productivity. This makes it difficult to work out a perfect connection between employee motivation and employer motivation because there are some different factors affecting their interests.

A de-motivator found in the research is the administrative difficulties with the university encountered by some work-based learners and their employers. Universities have been slow in changing their structures and processes to meet the needs of older learners studying on a part-time basis. 
Although there are varied views about the clarity of needs before undertaking the programmes, all employees had an idea about what they hoped to achieve at the end of the programme. This did not necessarily relate to needs in terms of the roles they play before undertaking the programme, but more of general professional development.

In most cases, the decision to undertake the study is employee-initiated. Even in employer-university partnership schemes it is more the willingness of the employees and their particular needs that drive the desire to take a higher education award. This could be one reason why there is not any formal or informal process supported by the employer to identify the things they hoped to get out of the project in most of the cases. Employers who are involved with cohort programmes to some extent based the projects on the needs of their organisations, although some of their employees appeared to go through the programme pursuing more personal/professional endeavours free from a close connection with the employer's needs. Again, this shows some variations in the needs of employees and employers and the employer-employee relationship. However, some employers also said that the individual development of the employee is the main purpose and need of the employer.

Employees' reasons for choosing the programme of study are generally related to the flexibility of the WBL programmes in which study is at a distance, requiring purposeful activities related to the workplace, non-regular or no direct lecture sessions and the absence of pre-planned syllabuses. The main reason emerging from the employers for choosing WBL is that it is convenient, it has direct relevance, fits well into work schedules and links the theoretical and intellectual side of things to the more practical day-to-day issues facing business. WBL awards are more directly relevant to work than awards that are more theoretically focused. Overall the rationale for employees and employers to undertake the programme has three main interrelated factors: convenience, meeting individual learning needs and an "opportunity seized".

All employee respondents are supported in one way or another by their employers regardless of whether they have formal/informal discussion or not; support ranges from paying full or part of financial cost of the programme, offering time off work and providing use of resources. Respondents who are self-employed pay the costs themselves. However, the level of employers' involvement in the design, delivery and/or assessment of the programme is limited in the sense that although some employers are in partnership with the university, it is often limited to just the formal partnership with an informal helping hand given to employees. The most involved third party is usually the case where the university is in partnership with an organisation that also has training provision and is involved at different levels in the design, monitoring and assessment of the programme. The value of the work-based project can therefore be enhanced through industry/academic links. In addition, self-employed individuals are actively involved (as employers) as a matter of course throughout the programme.

\section{Value}

It is not possible to gain a precise measurement of the economic value of WBL to employers and employees at the postgraduate level. There is an accepted faith from employees and employers that learning and employee development is a positive reward for staff and that WBL is more directly related to the employee's actual work than some other programmes of study.

In terms of the employees' financial gain there is a clear case for some of the participants whose attainment of masters or doctoral awards have positively impacted on the financial gains either as private consultants or changing to more financially rewarding roles or jobs. 
JWAM

7,1

An important value for money issue that emerged is how work-based projects can make the best use of resources (teaching and learning and work-based resources) and this is a learning issue as well as an economic one. If employers are to invest in WBL, a clear case needs to be made for how learners can use resources from a range of places. In making the case for how and where resources are accessed, the focus is both upon learning and on cost.

The answers to questions about the actual cost of undertaking the programme are vague and appear not to have great importance to postgraduate employees or their employers because the cost is relatively insignificant to them compared with the perceived benefits that could be gained from the programme. Those interviewed are more interested in the related cost benefit of service improvement through employee performance. It is difficult to find precise examples for a business case that WBL is or is not cost-effective in terms of benefit to employees and employers.

The profitability of WBL to HEIs may to some extent be measured through existing tools and techniques, however, knowledge of WBL modules and practices is needed to fully understand the model; for example, how the costs relating to accreditation and flexibly taught elements might be factored in.

In most cases the WBL experience had caused change to the employees themselves and to the way they undertake their work.

\section{Enhanced personal and professional confidence}

The culmination of a work-based project often brings about enhanced personal and professional confidence, aspirations and expertise. Enhanced personal expertise is expressed mainly in terms of proven high-level intellectual skills, usually involving skills of synthesis, better judgement of levels of achievement and "seeing the broader picture" and ability to act as self-motivated learners. Employees also acknowledged the difficulties and self-drive necessary to develop themselves to masters and doctorate level, based on a work-based programme.

Employees occupy significant positions such as managers/leaders in their organisations and work within complex and sensitive social and political environments that often have constraints and tight schedules that require the use of a rare combination of skills, knowledge, personal qualities and concern for values. They often express their expertise and attribute much of it to the autonomy they have on the programme to use a range of higher education approaches in the context of their actual work.

The will to continue to develop shows itself in the continuation of the employees' work-based projects as real-time ongoing activities at work. There are positive yet unforeseen effects on colleagues and clients, renewed interest in further learning, and productive engagement in debates relevant to the professional wider field.

\section{Enhanced personal and professional credibility}

There is a perceived greater status with clients and colleagues and recognition from professional groups for the higher education learning of their achievements and significantly increased self-confidence in themselves as employees and as professionals. In some cases enhanced credibility is seen for their professional communities as well as for them as individuals.

WBL programmes demand that employees have a certain positionality before they are allowed on the programme in terms of experience and status within their organisations or professional area, in that they have to be in a position to be able to impact on change. 
There is significant impact from the experience relating to the employees' enhanced credibility (real or perceived) in the eyes of others in their field who engaged more readily with their work once they had achieved masters and doctoral status. It is noted that the change in the employees themselves provided the impact. Employees variously achieve greater status for themselves and their organisations from the perspective of their peers and within themselves regarding their self-esteem.

The less tangible benefits of work-based projects are very clearly identified, for example prestige and credibility. Work-based projects are dependent on the context of

the work situation; the diverse features of the particular employer/employment/ organisation can make a great deal of difference. The less tangible values are difficult to articulate in the research yet many of the respondents alluded to more intrinsic than extrinsic benefits. A benefit of WBL to the individual learner can be juxtaposed with the benefit to the organisation so there is often a direct link with the value placed on the work by the employee and employer.

Personal benefits and impact are found by most employees as an important factor of the work-based projects. They frequently express a new-found confidence from undertaking work-based projects as part of a WBL programme. The term "opportunity" is used to demonstrate how they uncovered ways to gain greater insight, develop themselves further both as employees and as individuals. The programme changes career aspirations because of the feeling of empowerment and confidence. Participants record a greater understanding of both their fields of expertise and generic understanding of management, leadership and generally how things and people work. In particular there is evidence that increased knowledge of a particular area, writing skills, research skills and understanding of methodology and ability to publish has personal impact. Some experience the programme as life-changing and some experience a more long-term than immediate benefit.

Some participants find professional benefit a particularly important factor. Professional benefit is clearly thought to have significant impact on awareness and expertise in a particular area, an expert in the field with others in the organisation or professional field showing confidence in and acknowledgement of the participant's expertise. When employees receive the title of "Dr" in particular, it is seen as prestigious for the organisation.

\section{Direct benefit and impact to an organisation or professional area}

Direct impact on the candidates' organisations or professional areas came from work activity contained within their specific projects that made a real change to professional situations. However, overwhelmingly, the benefit to the employer is to raise the employers' credentials and prestige in the view of others. Other impactful benefits to the employer are improved work efficiency, ability to take on more demanding roles and being sought after as an expert. Some distinct benefits in terms of impact to the organisation are articulated by employers, for example, Mags Thomas, HRM Manager at Toshiba Tec, in relation to work-based projects undertaken by her employees stated "They gave us a discipline, a way of looking at the needs of our business".

Candidates undertaking the work-based projects recorded a greater understanding of both their fields of expertise and generic understanding of management, leadership and generally how things work and better communications with other people. In particular there is evidence of increased knowledge of a particular area, writing skills, research skills such as understanding of methodology and ability to publish. This enabled personal impact and confidence in themselves to take work projects 
JWAM

7,1

forward. It also earned them respect from other colleagues. Some had experienced the programme as life-changing and some experience a more long-term than immediate benefit. Credibility from their work context is important or more important to them than academic achievement.

The complexities of the projects and the position of the employees within them make it particularly difficult to map out all the benefits and impact of employees' learning experiences for themselves and their organisations/ employers, and more importantly to have a measurable sense of the benefits and impact.

The introduction of change in organisations can have both positive and negative outcomes. Employers often want compliance from employees who engage in WBL as well as innovative ideas. The critical faculties engendered through a higher education can sometimes be used to challenge organisational practices especially in that WBL confronts actual practice because the process of engagement is activity-based usually in the work situation itself. Previous studies have shown that where WBL is embedded in organisational learning there can be a conflict of interest between employees and the employer (Siebert and Costley, 2013). However, in our sample the employees appeared content that they are in a position where they could generate significant structural capital within an organisation and often also, their professional field.

\section{Recommendations}

To strengthen the impact of WBL and to make it more beneficial to all stakeholders, the following recommendations are offered.

Link individual and organisational learning more effectively. How can universities work with organisations to create learning environments that capitalise on the learning? The tripartite relationship between employers, employees and higher education providers could be developed upon and used positively to increase the impact and benefit of WBL. Programmes could be firmly linked to the needs and expectations (structural capital) with individual learning needs and organisational development needs. Programmes could provide individuals with opportunity for reward/development and also create a potential impact on organisational knowledge. The needs of the employees should be further taken up and analysed. The needs of the employers require much more work in closely thought through joint research and development between HEIs and organisations and other stakeholders.

At the heart of the WBL process is the work-based project that shows the results of improvement in practice, which should be based on evidence at all relevant levels - individual, organisational and through professional bodies and other stakeholders. Developing instruments to get this right would be particularly beneficial. The advantages of practitioner-research projects need more scrutiny by higher education academics, employer organisations and other stakeholders. This is a crucial recommendation for employers who could contribute more to universities' understanding of the needs of work-based projects.

The consideration of a WBL pedagogy can be made in more detail and could centre on employees' current and prior learning and build from their current understanding where possible. This requires particular pedagogical understanding of people's learning at work and of the nature of knowledge in work settings. It also requires employers to build this understanding into their structures, for example, through appraisal and promotion mechanisms.

The outcome and the nature of the methodologies followed by practitioners in their research and development activities appear to be an important topic for higher 
education researchers to explore. The links between practitioner research and research methodologies need further development as this is a key area for practitioners to enhance their working practices especially at postgraduate and doctorate level. Research approaches and methodologies have been an important development in universities. Qualitative research has been at the forefront of these initiatives (Denzin and Lincoln, 2003). Pure and applied approaches to knowledge have been a standard feature in universities for many years but the work-based research projects are not an applied version of an existing theory. They have more in common with research and development traditions and/or Levi-Strauss's notion of the bricoleur.

Higher education providers should recognise the complexities of WBL and change their existing processes and structures to effectively accommodate these new approaches to learning. Administrative structures and other procedures of many HE providers are still based on the more traditional approach whereas WBL involves more engagement with third party experts in work and learning, i.e. not just the university/ student relationship. It also means more flexible approaches on-line, multiple sources of knowledge, e.g. from the professional sphere and accreditation networks of knowledge and communities of practice make it more relevant for work-based learners to benefit fully from programmes.

Subject discipline criteria and generic criteria provide differing approaches to WBL. More research could be done on generic abilities at high levels and how these factor in postgraduate programmes. Traditional disciplines served different kinds of societies.

Embedding employer responsive provision across universities should be a priority and for this to be successfull the further development of cross-functional teams is recommended; academics, business development personnel, administrator and others all working together to meet the needs of organisations and their employees. A key recommendation of the Higher Education Funding Council for England is for important labour market information and knowledge to be fed back into programme development,recording the needs of employees and organisations at every level, e.g. academic, structural, time and resource issues.

Critical reflections by stakeholders on how WBL programmes are built into overall learning strategies of organisations could enhance the fitness of and fitness-for-purpose component of programmes. This could be achieved through developing partnerships between HEIs, employers, employees and other stakeholders that are operated and guided by the principles of transparency, mutual agreement and benefits, and clear understanding of structures and strategies to ensure a balance of "power and influence" in the process. Employers would develop interest and actively engage with their employees' WBL through involvement in the processes of design, delivery and assessment of the programmes. This is also a key recommendation of the Wilson Report in the UK (Wilson, 2012). Professional bodies could engage in and reflect more on the outcomes of WBL and engage in a reflective discussion with universities and employer organisations. Other stakeholders, for example Learning and Skills Councils and employer organisations, could be involved in these important partnerships that would all be working towards more effective learning for, in and through work. How the relevant partners understand and use these relationships and the values they have and might have in future are likely to determine the success of these partnerships. 
JWAM

7,1

\section{Conclusion}

This research suggests that the impacts of WBL projects are both specific and general. While it is difficult to differentiate between personal benefits and professional benefits of the projects to employees, undertaking work-based projects is seen as generally beneficial to employees. Broad personal benefits are: better understanding of issues related to job roles, developing self-confidence, raising personal status, e.g. being called a doctor and building knowledge and skills of research and researching at the workplace. The professional benefits to employees include enhancing professional credentials and credibility, and establishing their expertise in their professional areas of practice.

The work-based projects are of benefit to employers in terms of adding value to their (employees) job roles and raising the prestige and credentials of the organisations to existing and potential clients in ways that increased output and profit.

Further research and publications undertaken after the work-based projects had concluded by mostly WBL doctoral graduates have led to continued enriching and expanding practitioner knowledge, based in areas such as training and development.

A key addition to learning for the WBL employees/students is their fuller understanding of research methodology. A particular module, research and development for professional practice, prepared them for research and development projects. The positionality of the worker is important because the action involved in accessing data at work and then going on to develop and apply the research findings requires the agency of the researcher.

Employers and employees find that the academic knowledge applied to work-based projects when built upon the employees' existing work is able to bring about significant change and/or enhancement to work practices.

Cohort-based learners have the added advantage of a close group of other learners providing: peer support, more support from employers and clear and common goals. Those on individually negotiated programmes tend to find these advantages by engaging in their own networks of support and relying on themselves as autonomous learners to define more career-focused goals.

Customised programmes of WBL, constructed for different reasons and from a variety of viewpoints especially those on the nature of knowledge at work, produce data from which it is difficult to generalise. WBL academics are led by the learning needs of the employees and employers while the nature of the knowledge in which they engage is treated with relatively few problems. Consequently, in customising WBL by working with employers to formulate a programme of study or through individual negotiated programmes, what emerges is a view of knowledge that is difficult to codify against higher education structures. This is likely to be because work-based knowledge has a "real world" complexity not yet fully conceptualised in higher education.

A Practice Turn (Shatszi et al., 2003) has marked long and emerging theories of practice, e.g. that are now being used to theorise this emergent are of the higher education curriculum. This research demonstrates the above emerging themes that relate to what is found important by employers and employees. A question that arises from the research is the extent to which theories of practice that shed new light on WBL may be emerging and how they relate to existing literature.

Work-based projects use the expertise of HE learning in, for example, research, evaluation, synthesis and critical thinking to enable practitioners to use the workplace and its resources for development and innovation.

The projects allow employees to solve problems but more importantly to articulate their learning and the learning of their organisation or professional area. The projects 
provide a clear trail of work-based activity that, to a certain extent, measure the extent of the learning undertaken during the work-based programme.

Some of the concerns relating to work-based projects undertaken for academic purposes are that the project becomes an academic construct that may not be embedded too clearly in the everyday processes of working rhythms. Projects, after all, even if interpreted broadly, are only one of the activities in which workers engage. In this sense work-based projects can be seen as mechanistic and quantifiable. However, the projects are able to provide a "snapshot" of an individual or group of individuals" ability to innovate, change or improve a working situation. Projects provide an opportunity to:

(1) delve into a theoretical and conceptual domain;

(2) research and develop using an informed and rigorous process; and

(3) realise a range of possible pathways and possibilities for working practices.

The impact of WBL projects on employees is positive but challenging in some cases. The positive side is that some employees established themselves firmly in their organisations and areas of practice as experts; they have written books, conducted research and pushed the frontier of knowledge in those areas. However, there are indications that undertaking WBL could challenge employees' prospects and relationship with their employers.

Undertaking a work-based project offers depth of understanding, insight, confidence in themselves and confidence from colleagues. It is likely that any kind of reflective, thought-provoking educative experience may have made a difference to the employee or employer/organisation. A question is therefore whether a WBL programme has a greater and more relevant impact than any other programme of study. A key point is that the products of WBL masters and doctoral projects can contribute directly to positive impact on company processes and products. In this way WBL enables this practical learning which may be then underpinned by theory, to be valued by both HEIs and employers.

\section{References}

Costley, C. and Critten, P. (2012), "The business value of structured workplace learning”, Global Focus Magazine, Vol. 6 No. 1, pp. 14-17, available at: http://eprints.mdx.ac.uk/9213/ (accessed 5 September 2015).

Denzin, N.K. and Lincoln, Y.S. (2003), Handbook of Qualitative Research, 3rd ed., SAGE, London.

Garnett, J., Portwood, D. and Costley, C. (2004), Bridging Rhetoric and Reality: Accreditation of Prior and Experiental Learning (APEL) in the UK, Universities Vocational Awards Council, Bolton.

Garnett, J., Workman, B., Beadsmoore, A. and Bezencenet, S. (2008), "Workforce development", Developing the Structural Capital of Higher Education Institutions to Support Work-Based Learning Programmes, The Higher Education Academy, New York, NY.

Gibbs, P. and Garnett, J. (2007), "Work based learning as a field of study", Research in Post-Compulsory Education, Vol. 12 No. 3, pp. 409-421.

Lave, J. and Wenger, E. (1991), Situated Learning: Legitimate, Peripheral Participation, Cambridge University Press, Cambridge, MA.

Lester, S. and Costley, C. (2010), "Work-based learning at higher education level: value, practice and critique", Studies in Higher Education, Vol. 35 No. 5, pp. 561-575.
Work-based research projects 
JWAM

7,1
Lincoln, Y.S. and Guba, E.G. (2000), "Paradigmatic controversies, contradictions, and emerging confluences", in Denzin, N.K. and Lincoln, Y.S. (Eds), Handbook of Qualitative Research, SAGE, London, pp. 163-188.

Neuman, W.L. (2003), Social Research Methods - Qualitative and Quantitative Approaches, Allyn and Bacon, London.

Nixon, I., Willis, K., Major, D., Young, D., Tongue, A., Costley, C., Abukari, A., Biddle, P., Graham, S., McClenaghan, K., Helyer, R., Beadsmoore, A., Karuk, V., Siara, B. and Urwin, P. (2008), Work-Based Learning Impact Study, Higher Education Academy, York.

Schatzki, T.R., Knorr Cetina, K. and von Savigny, E. (Eds) (2001), The Practice Turn in Contemporary Theory, Routledge, London and New York.

Schwandt, T.A. (1998), "Constructivist, interpretivist approaches to human inquiry”, in Denzin, N.K. and Lincoln, Y.S. (Eds), The Landscape of Qualitative Research: Theories and Issues, SAGE, London, pp. 221-259.

Shaw, P. (2002), Changing Conversations in Organisations - a Complexity Approach to Changes, Routledge, London.

Siebert, S. and Costley, C. (2013), "Conflicting values in reflection on professional practice”, Higher Education, Skills and Work-based Learning, Vol. 3 No. 3, pp. 156-167.

Wilson, T. (2012), A Review of Business-University Collaboration, BIS, London.

\section{Corresponding author}

Professor Carol Costley can be contacted at: c.costley@mdx.ac.uk

For instructions on how to order reprints of this article, please visit our website: 